\title{
Semi-solid Sintering of Ti6Al4V/CoCrMo Composites for Biomedical Applications
}

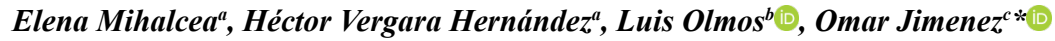 \\ ${ }^{a}$ División de Estudios de Posgrado e Investigación, Instituto Tecnológico de Morelia - TecNM, Av. \\ Tecnológico \# 1500, C.P. 58120, Colonia Lomas de Santiaguito, Morelia, México \\ ${ }^{b}$ Instituto de Investigaciones en Ciencias de la Tierra - INICIT, Universidad Michoacana de San \\ Nicolás de Hidalgo, Fco. J. Mujica S/N, C.P. 58060, Morelia, México \\ 'Universidad de Guadalajara, Departamento de Ingeniería de proyectos - DIP, José Guadalupe \\ Zuno,48, C.P. 45100, Los Belenes, Zapopan, México
}

Received: June 04, 2018; Revised: October 25, 2018; Accepted: December 06, 2018

\begin{abstract}
A composite of Ti6Al4V reinforced with CoCrMo particles is fabricated by conventional powder metallurgy and semi-solid sintering. Composites are fabricated by mixing $20 \%$ wt. of CoCrMo reinforcing particles into the Ti6A14V matrix. Sintering is studied by dilatometry tests between 1050 and $1130^{\circ} \mathrm{C}$ and compact characterization is performed by SEM and XRD. Microhardness is evaluated on the polished surface in order to obtain the mechanical properties. It is found that densification is achieved by the formation of a liquid phase due to a eutectic point formed by the Ti and $\mathrm{Co}$ at around $1130{ }^{\circ} \mathrm{C}$. Composites with $93 \%$ of relative density are obtained. Their microstructure is composed by the Ti6Al4V matrix surrounded by a $\mathrm{Ti}_{2} \mathrm{Co}$ phase. Average microhardness of composites is higher than that obtained for monolithic samples of both alloys. It is assessed that the control of the liquid phase is the key to obtain highly dense composites that could be used as dental or orthopedic implants.
\end{abstract}

Keywords: Ti6Al4V, CoCrMo, semi-solid sintering, composites, microhardness.

\section{Introduction}

Nowadays Ti based alloys and Co based alloys are the materials more commonly used to fabricate biomedical implants ${ }^{1-4}$. Existing researches on the subject were focused on tailoring the mechanical properties of the Ti6Al4V alloy to those of the real bones ${ }^{5,6}$. In order to reduce the stress shielding and to improve the citocompability, materials with large pores were developed by using different fabrication techniques ${ }^{7-9}$ where space holder ${ }^{10-12}$ and additive manufacturing ${ }^{13-15}$ are the most promising. Nevertheless, the wear properties of the Ti6A14V alloy are relatively low, thus, several works were dedicated to improve the surface properties. In order to overcome this disadvantage, coatings of harder materials were realized ${ }^{16-18}$. However, the adhesion and elastic modulus mismatch between the coating and the Ti6Al4Vcould lead to delamination or cracking, which generates doubts in their use on a long term. Other works, dealing with improving wear properties, developed composites materials based on the Ti6Al4V alloy with ceramic reinforcing particles, which presented good results, improving up to 2 times the hardness of the Ti6Al4V alloy ${ }^{19-22}$.

On the other hand, CoCrMo alloy is used to fabricate medical implants such as hips, knees, ankles and bone plates because of its high fatigue, wear and corrosion resistance ${ }^{23-26}$. Most of CoCrMo devices are fabricated by casting, however materials processed by powder metallurgy have shown similar properties and even higher when the alloy is enriched by micro alloying elements ${ }^{27,28}$. The main disadvantage of this alloys is its weight, compared with that of the human bones and the Ti alloys. With the aim to reduce the stress shielding, graded porous compacts of $\mathrm{CoCrMo}$ were fabricated by laser engineered net shaping (LENS), nevertheless the values of Young's modulus found by España et al. ${ }^{4}$ are still higher with respect to the cortical bone.

Recently, alloys of Ti-Co were designed for dental applications because of the lower melting point in comparison to the Ti6Al4V and the CoCrMo, as well as the higher values of hardness and good stability of such alloys ${ }^{29-30}$. Based on the Ti-Co binary phase diagram, eutectic reactions may occur above $1020^{\circ} \mathrm{C}$, depending of the weigh percent of $\mathrm{Co}^{31}$. Even though those alloys have a lower melting point, processing by casting involves a cooling inside a mold that will require further post processing steps to obtain the final part. To overcome this disadvantage, powder metallurgy (PM) technique offers a good alternative to obtain compacts by semi-solid sintering. This method was successfully used to produce aluminium and magnesium alloys ${ }^{32}$. Just a few works were devoted to study the semi-solid sintering of Tialloys mixed with elements like $\mathrm{Fe}, \mathrm{Co}, \mathrm{Nb}$ and $\mathrm{Al}^{33,34}$. They found bimodal microstructures with superlative compressive strength and plasticity. The major complexity of this method is to control the eutectic solution created during the thermal cycle because the viscosity of the eutectic liquid is reduced as the temperature and/or sintering plateau increases. This is detrimental for the distribution of the secondary phase created, as well as for the final shape of the compact. 
The objective of this work is to study the semi-solid sintering of Ti6Al4V/20\%CoCrMo composite by dilatometry in order to assess better conditions to control the eutectic reactions and evaluate the microstructure and mechanical properties as a function of the sintering conditions.

\section{Materials and Methods}

Atomized prealloyed Ti6Al4V and CoCrMo metal powders with spherical particles smaller than $45 \mu \mathrm{m}$, see Figs. 1a and $1 b$, produced by Raymor, Quebec, Canada and SANDVIK Osprey $^{\mathrm{TM}}$, Sweden, respectively, were used to fabricate a composite. CoCrMo was added in $20 \mathrm{wt} \%$ with respect to the Ti6Al4V powders and were mixed in a Turbula during $30 \mathrm{~min}$ in dry conditions. In order to observe the distribution of CoCrMo powders, the mixture was poured into a quartz capillary of $1 \mathrm{~mm}$ internal diameter. Next, a 3D image was acquired with a Zeiss 510 Xradia Versa computerized microtomographer (CMT. 1600 projections were taken around $360^{\circ}$ of the sample with a CCD camera of $1024 \times 1024$ pixels with a voxel resolution of about $1 \mu \mathrm{m}$. Fig. 1c shows a $2 \mathrm{D}$ virtual slice of the mixture and Fig. $1 \mathrm{~d}$ shows a $3 \mathrm{D}$ rendering of mixture in where can be noticed that CoCrMo particles are randomly distributed in the mixture. After the mixture of the powders, $1 \%$ wt. of polyvinyl alcohol (PVA) was added as a binder. Next, the mixture was poured into an $8 \mathrm{~mm}$ diameter stainless steel die and pressed at $500 \mathrm{MPa}$ using an Instron 1150 universal machine to obtain cylindrical compacts of $4 \mathrm{~mm}$ height. Next, the PVA was thermally extracted by a slow heating at $5{ }^{\circ} \mathrm{C} / \mathrm{min}$ up to $500{ }^{\circ} \mathrm{C}$ with a dwell time of $40 \mathrm{~min}$ in argon atmosphere. Afterwards, each compact was sintered in a Linseis $\mathrm{L} 75 \mathrm{~V}$ vertical dilatometer in the range of $1000-1130{ }^{\circ} \mathrm{C}$ with a dwell time of $5 \mathrm{~min}$ in argon atmosphere. The heating rate varied during sintering, from 500 to $1050{ }^{\circ} \mathrm{C} 20^{\circ} \mathrm{C} / \mathrm{min}$ was used, then from $1050{ }^{\circ} \mathrm{C}$ up to reach the sintering plateau, the heating rate was $5^{\circ} \mathrm{C} / \mathrm{min}$. This measure was taken to ensure that the temperature reached during the thermal cycle was close to that desired because the inertia of the furnace can increase by 10 or $20^{\circ} \mathrm{C}$ the temperature when higher heating rates are used. The weight density of every sintered compact was calculated from mass and dimension measurement.

The sintered samples were cut and surface-polished with $\mathrm{SiC}$ abrasive papers and alumina powders (until 50 $\mathrm{nm}$ particle size), successively for SEM observation. The microstructure was observed with a Tescan MIRA 3 LMU field emission scanning electron microscope (FE-SEM). Samples were directly observed without any conductive coating and the acceleration voltage used to acquire the FESEM images was set at $20 \mathrm{keV}$ by using secondary electrons. The crystalline structure was assessed by X-ray diffraction (XRD) using a PANalytical Empyrean difractometer. The XRD patterns were obtained by using the $\mathrm{K}$ alpha copper radiation with an energy of $30 \mathrm{kV}$ and $30 \mathrm{~mA}$, with a step size of 0.2 and a time step of $1 \mathrm{~s}$ in the range of $30-90^{\circ}$. Finally, a micro-hardness evaluation was performed on cross-sectional polished surfaces via a micro-hardness tester from Mitutoyo MVK-HVL with a load of $10 \mathrm{gf}$ and a dwell time of $15 \mathrm{~s}$. Indentations were made on the different phases obtained after sintering process.

\section{Results and Discussion}

\subsection{Dilatometry}

Global density can be obtained from:

$$
\rho=\frac{m}{v}
$$

Where $\rho$ is the density, $m$ and $V$ mass and volume of the compact. Assuming that $\mathrm{m}$ is constant during the whole sintering cycle the instantaneous density can be calculate as:

$$
\rho_{i}=\frac{m}{v_{i}}
$$

In where the subscript " $i$ " means instantaneous density and volume, respectively. The instantaneous volume depends on the densification during sintering and it can be estimated from the dilatometry data, in where, the radial displacement is assumed to follow the same variation as the measured
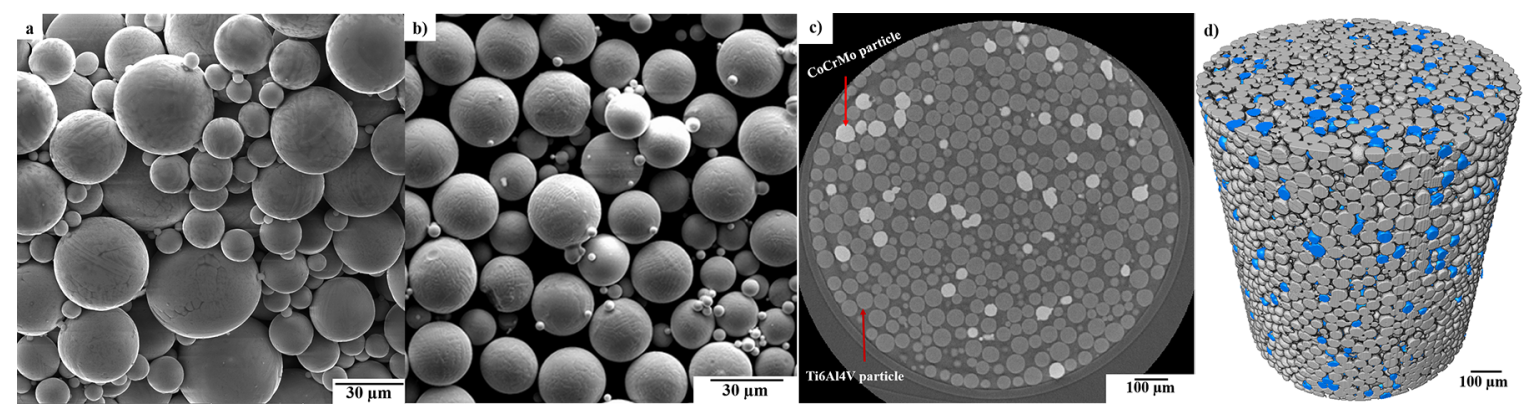

Figure 1. SEM micrographs of the initial powders: a) Ti6Al4V and b) CoCrMo and tomographic images: c) 2D virtual slice and d) 3D rendering of the powder mixture. 
axial one, with a corrective factor being the final axial to radial shrinkage ratio. Thus, the instantaneous volume can be obtained from:

$$
V_{i}=\left(\Delta l+\Delta l_{o}\right)\left(\Delta d+\Delta d_{o}\right)^{2}(\pi / 4)
$$

In where $\Delta \mathrm{l}$ and $\Delta \mathrm{d}$ can be measured at any instant during the thermal cycle. The relative density is defined as the weight density of the compact divided by the theoretical density of the fully dense Ti6Al4V/CoCrMo composite at room temperature, which was calculated by using the mixture law:

$$
\rho_{t}=\rho_{1} f_{1}+\rho_{2} f_{2}
$$

Where $\rho_{\mathrm{i}}$ and $f_{\mathrm{i}}$ are the theoretical density and the volume fraction of component $i$. Therefore, the relative density can be estimated during the complete sintering cycle as follows:

$$
D=\frac{\rho_{i}}{\rho_{t}}
$$

Relative density as a function of the temperature during the whole thermal cycle is shown in Fig. 2a. It can be observed a small increase of the density around $500^{\circ} \mathrm{C}$ that is due to the elimination of the PVA. Next, around $900{ }^{\circ} \mathrm{C}$ the solid state sintering between Ti6Al4V particles is noticed by a continuous increment in the relative density till the sintering plateau is reached. During the plateau, a linear increase in the relative density is observed. Finally, a linear increase in the relative density is due to the cooling stage of the thermal cycle. It can be clearly noted that relative density progressively increased as the sintering temperature is raised. However, when the sintering temperature reached $1130{ }^{\circ} \mathrm{C}$ a sharp increase is detected, by increasing the final relative density from $83 \%$ at $1120{ }^{\circ} \mathrm{C}$ up to $93 \%$ at $1130{ }^{\circ} \mathrm{C}$. This indicates the formation of the liquid phase that can fill the interparticle pores that remain interconnected. This liquid phase is obtained due to the eutectic point formed by the combination of $\mathrm{Ti}$ and $\mathrm{Co}$ that leads to the $\mathrm{Ti}_{2} \mathrm{Co}$ eutectic phase, as it is indicated in the phase diagram of both elements ${ }^{31}$.

The instantaneous densification rate $\dot{D}$ can be estimated as follows ${ }^{35}$ :

$$
\dot{D}=\frac{d D_{i}}{d t_{i}}=\frac{D_{i}-D_{i-1}}{t_{i}-t_{i-1}}
$$

Where $D_{i}$ is the instantaneous relative density at time $t_{i}(s)$, for and interval of $t_{i}-t_{i-1}$ of $3 \mathrm{~s}$. Fig $2 b$ shows the densification rate as a function of the temperature during the densification stage, which started around $700{ }^{\circ} \mathrm{C}$. Between the beginning of the densification and $1050^{\circ} \mathrm{C}$ similar behavior is noticed in all samples. That means an increase of the densification rate, which could be associated to the rearrangement of the particles inside the packing before $850{ }^{\circ} \mathrm{C}$. After that, a small decrease in the densification rate is noticed between 850 and $870^{\circ} \mathrm{C}$, which can be associated with the Titanium crystalline phase transition from $\alpha$ to $\beta$. Then, an increase in the densification rate is noticed till around $940^{\circ} \mathrm{C}$, which confirms the end of the transition to $\beta$ phase. Next, a linear increase in the densification rate is noticed up to $1050^{\circ} \mathrm{C}$, which is associated with the solid state sintering and the start of the formation of the eutectic phase. Then, samples sintered at higher temperatures than $1050{ }^{\circ} \mathrm{C}$, shows a decrease in the densification rate, that is logical since the heating rate is reduced from 20 to $5^{\circ} \mathrm{C} / \mathrm{min}$. Nevertheless, the sample sintered at $1130^{\circ} \mathrm{C}$ shows a sharp increase in the densification rate at $1125^{\circ} \mathrm{C}$ indicating that a liquid phase is formed. The densification rate increased around ten times between $1125^{\circ} \mathrm{C}$ and $1130{ }^{\circ} \mathrm{C}$.

In order to estimate the activation energy during sintering it should be taken into account the fact that the formation of the eutectic phase will induce the viscous flow to redistribute the matter inside the compact, in where the viscosity is directly influenced by the sintering temperature. The first

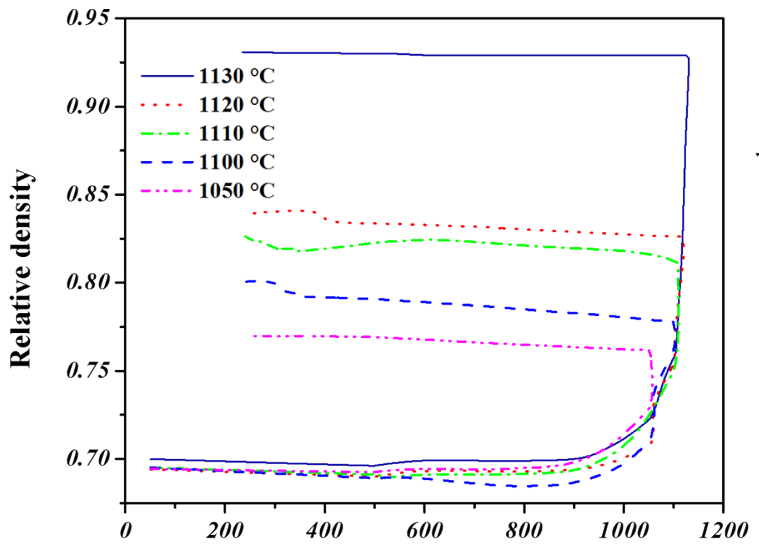

(a) Temperature $\left({ }^{\circ} \mathrm{C}\right)$

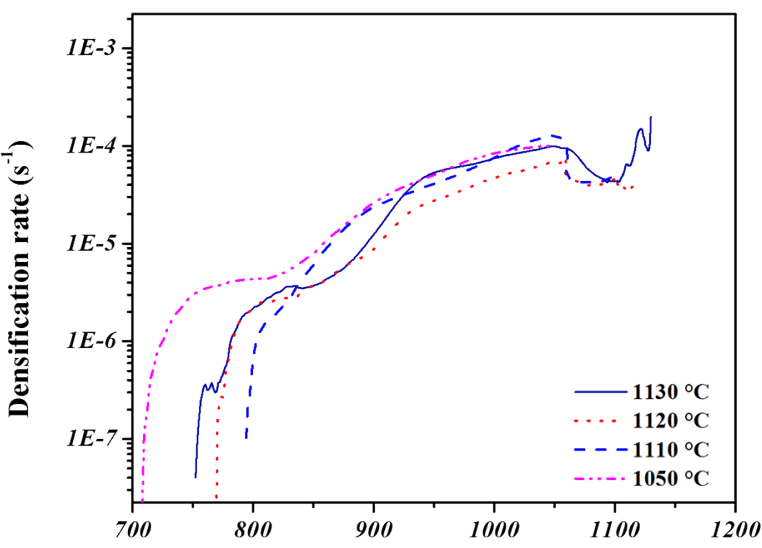

(b) Temperature $\left({ }^{\circ} \mathrm{C}\right)$

Figure 2. a) Relative density as a function of the temperature during sintering, and b) shrinkage rate as a function of the temperature. 
model to estimate the shrinkage under a viscous flow was proposed by Frenkel ${ }^{36}$ :

$$
\frac{\Delta l}{l_{o}}=\frac{3 \gamma}{4 \varnothing \eta} t
$$

In where $\Delta \mathrm{l} / l_{0}$ is the axial shrinkage of the compact, $\gamma$ the surface energy, $\eta$ the viscosity of powders, $\varnothing$ the particle diameter and $t$ the time. Viscosity follows an Arrhenius relationship over a range of temperatures as follows:

$$
\eta=\eta_{0} \exp \left(\frac{Q}{R T}\right)
$$

In where $\eta_{0}(\mathrm{~Pa} \cdot \mathrm{s})$ is a viscosity coefficient, $\mathrm{Q}$ activation energy, $\mathrm{R}$ universal gas constant $(8.314 \mathrm{~J} / \mathrm{mol})$ and $\mathrm{T}$ the temperature $(\mathrm{K})$. Equation (8) is possible to be written as ${ }^{35,37}$ :

$$
\ln \left(\frac{d\left(\Delta l / l_{o}\right)}{d T}\right)=\ln \left(\frac{3 \gamma}{4 D c \eta_{o}}\right)-\frac{Q}{R T}
$$

Assuming that $\ln \left((3 \gamma) /\left(4 \mathrm{Dc} \eta_{0}\right)\right)$ are constants of powders, the Arrhenius plot $\left(\ln \left(\mathrm{d}\left(\Delta \mathrm{l} / \mathrm{1}_{0}\right) / \mathrm{dT}\right)\right.$ vs $\left.1 / \mathrm{T}\right)$ for the sintered samples between 1000 and $1130{ }^{\circ} \mathrm{C}$ can be plotted as shown in Fig. 3. To calculate the value of $\mathrm{Q}$, a linear regression is performed, and the value of the slope of the points corresponds to $\mathrm{Q} / \mathrm{R}$. In Fig. 3 is clearly observed a break point of the straight line at around $1100{ }^{\circ} \mathrm{C}$. Because of that, the data were separated in two slopes, above and below $1100{ }^{\circ} \mathrm{C}$, thus, two activation energies were estimated. The first one $\mathrm{Q}_{1} 252 \mathrm{~kJ} / \mathrm{mol}$, is in agreement with the values reported for volume diffusion mechanisms during the solid state sintering of the Ti6Al4V alloy ${ }^{38}$. This indicates that shrinkage in temperatures lower than $1100{ }^{\circ} \mathrm{C}$ is driven by the formation and growth of necks between Ti6Al4V-Ti6Al4V particles. Contrary, the estimated $\mathrm{Q}_{2}(670 \mathrm{~kJ} / \mathrm{mol})$ is much higher than $\mathrm{Q}_{1}$, which indicates a change in the diffusion mechanism. There is a possibility that the higher activation energy is due to the reaction generated by the formation of the eutectic phase as well as for the reduction in the viscosity of the liquid formed.

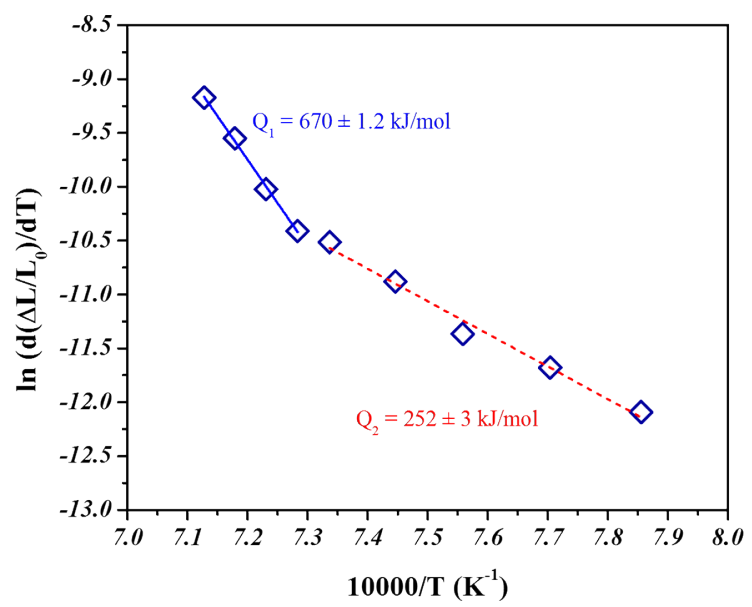

Figure 3. Arrhenius plots of $\ln \left(\mathrm{d}\left(\Delta \mathrm{l} / \mathrm{l}_{0}\right) / \mathrm{dT}\right)$ vs $1 / \mathrm{T}$ for estimating activation energies.
Higher values of activation energy were found in ceramics systems, which are caused by the addition of titanium and zirconia in order to dope alumina powders ${ }^{39}$. Nevertheless, no report about this behavior has been found for the Ti-Co system. Even if the active diffusion mechanisms during the densification are not clear yet, it can be established that above the temperature of $1100{ }^{\circ} \mathrm{C}$ densification is driven by the semi-solid state of the eutectic phase.

\subsection{SEM observation}

Fig. 4 shows the microstructure of composites sintered at 4 different temperatures. Fig. 4a presents the sample sintered at $1050{ }^{\circ} \mathrm{C}$, in which is possible to notice that CoCrMo particles are no longer spherical. This is because a decomposition of the initial particles occurs by diffusion of the Co on the surface of the Ti6A14V particles. It can also be observed the formation of interparticle necks between Ti6Al4V particles due to the solid state diffusion. However, interparticle pores remain in the microstructure because sintering is in the initial stage. Fig. $4 \mathrm{~b}$ shows the microstructure of the sample sintered at $1100{ }^{\circ} \mathrm{C}$ and it is noticed that CoCrMo particles (the white surfaces in the image) reduced their size and completely changed their shape. It can be clearly observed in the figure the Ti6Al4V particles (dark grey) and a reaction zone around the CoCrMo particles (light grey), which corresponds to the eutectic phase formed by the diffusion of the cobalt in the titanium. The eutectic phase spreads around the Ti6Al4V particles but the composite still presents some large pores. By increasing the sintering temperature at $1120{ }^{\circ} \mathrm{C}$, Fig. $4 c$, it's observed that the eutectic phase increases and interparticle pores diminished, although the center of the CoCrMo particles it's still visible in the microstructure. In the case of sintering at $1130^{\circ} \mathrm{C}$, Fig. $4 \mathrm{~d}$, the CoCrMo particles cannot be distinguished anymore because the eutectic phase forms a liquid that can fill most of the porosity, but some large pores still remain in the composite. Such pores could be created during the packing and they are difficult to fill by liquid phase.

With the aim to confirm the formation of the eutectic phase and the distribution of the phases on the observed surface, an EDS elemental mapping of the Ti and Co was performed, Fig. 5. In Fig. 5a is shown a CoCrMo particle surrounded by Ti6Al4V particles after sintering at $1050^{\circ} \mathrm{C}$. It's observed the decomposition of the surface of the CoCrMo particle and the eutectic liquid like small rivers between the Ti6Al4V particles and at the contacts with the CoCrMo particle. Figs. $5 \mathrm{~b}$ and $5 \mathrm{c}$ shows the distribution of the $\mathrm{Ti}$ and Co elements on the surface. It's clearly observed that Co is mainly distributed in the "rivers", meanwhile the $\mathrm{Ti}$ element is distributed homogeneously around the CoCrMo particle. The CoCrMo particle looks like a darker zone in the figures, as the surface of the CoCrMo particle is slightly below the analyzed surface and the detector cannot send a good signal. Nevertheless, the most important conclusion 


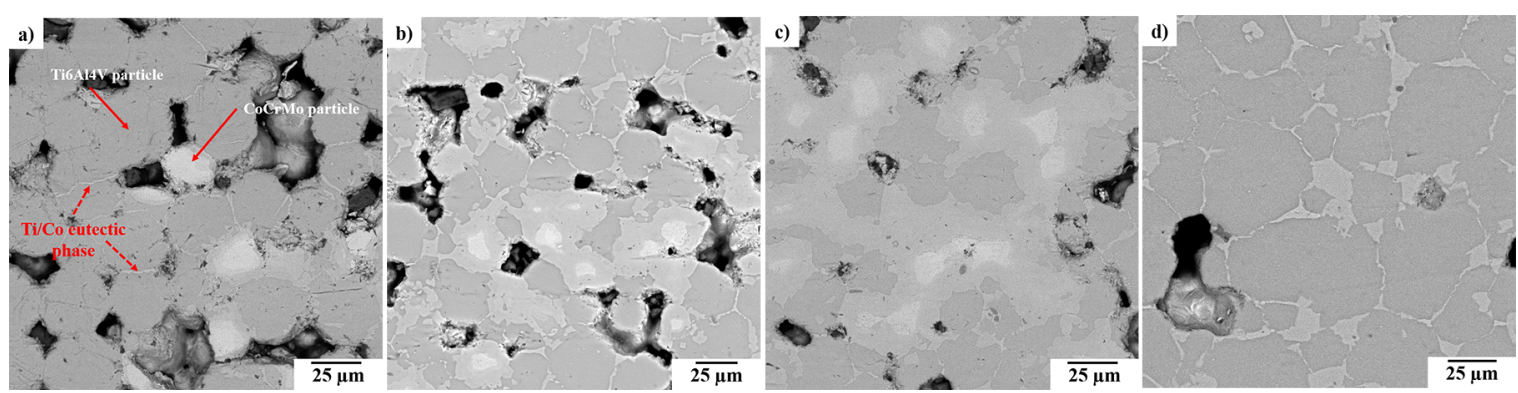

Figure 4. SEM micrographics of the composite after sintering at different temperatures, a) $1050^{\circ} \mathrm{C}$, b) $1100^{\circ} \mathrm{C}$, c) $1120^{\circ} \mathrm{C}$ and d) $1130{ }^{\circ} \mathrm{C}$
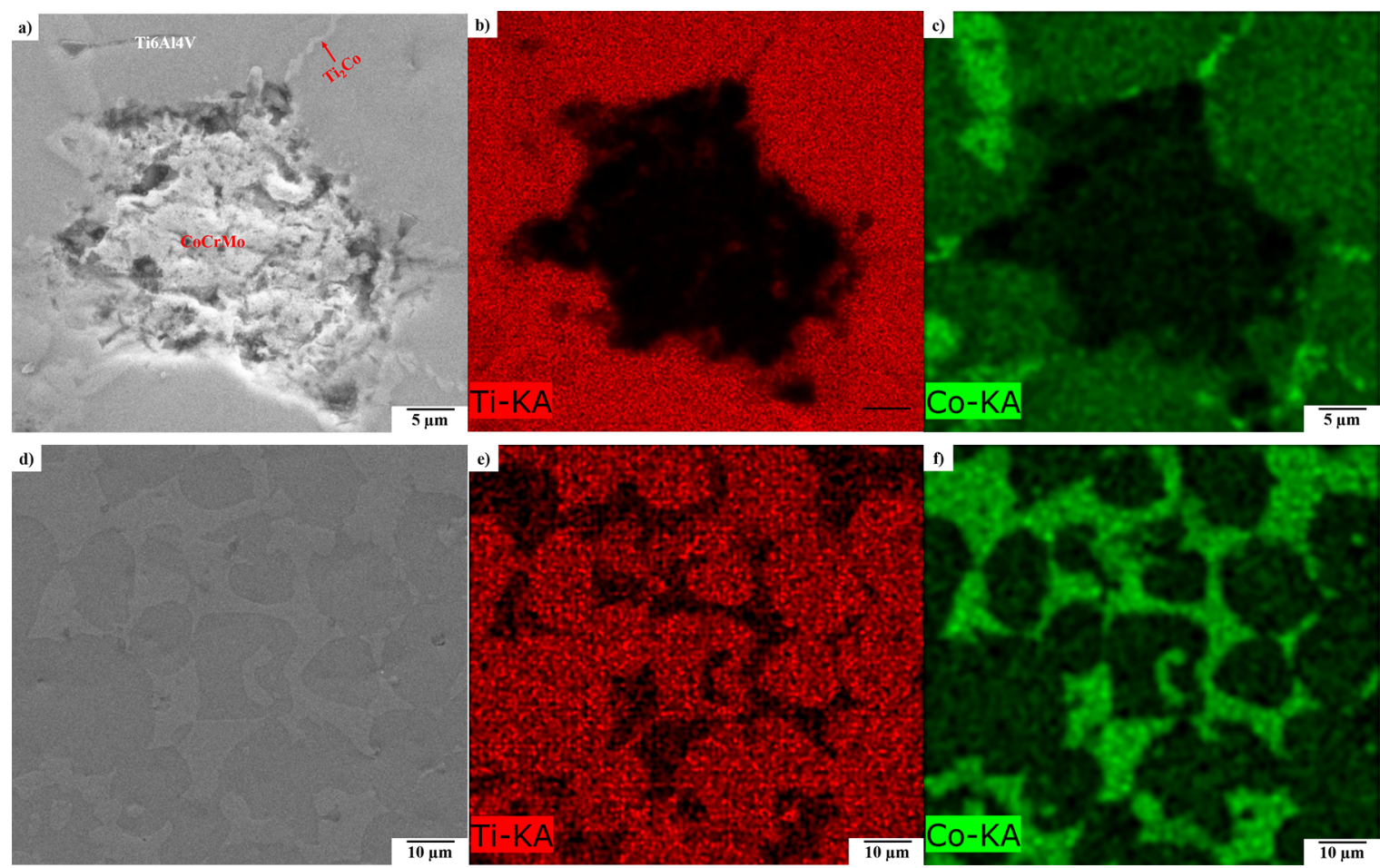

Figure 5. EDS elemental mapping of the composite Ti6A14V/CoCrMo at different temperatures: a), b) and c) $1050{ }^{\circ} \mathrm{C}$ and d), e) and f) $1130{ }^{\circ} \mathrm{C}$.

from images $5 \mathrm{a}, \mathrm{b}$ and $\mathrm{c}$, is that the diffusion of Co into Ti starts earlier than predicted by the phase diagram and that the eutectic phase begins to expand on the surface of the Ti6Al4V particles.

Fig. $5 \mathrm{~d}$ shows the surface of the sample sintered at $1130^{\circ} \mathrm{C}$, in which the CoCrMo particles are not visible anymore. The distribution of the Ti and Co on the surface is shown in Figs. $5 \mathrm{e}$ and 5f, respectively. It's observed that $\mathrm{Ti}$ is predominant mainly in the matrix of the composite meanwhile the Co is concentrated in the eutectic phase, although the $\mathrm{Ti}$ is also present in the eutectic phase.

With the aim to assess the composition of the eutectic phase formed during sintering, a line scan was realized along the Ti6Al4V matrix and the eutectic phase, for the sample sintered at $1130{ }^{\circ} \mathrm{C}$, see Fig. 6. It's observed that eutectic phase is composed of $\mathrm{Ti}$ and $\mathrm{Co}$, with a ratio of $70 \mathrm{Ti} / 30 \mathrm{Co}$. It can also be noticed that eutectic phase is localized between the Ti6Al4V particles, which suggest that the diffusion of $\mathrm{Co}$ is superficial. With this analysis the diffusion of $\mathrm{Cr}$ and $\mathrm{Mo}$ is not possible to be detected because of the small quantity of this components. It is assumed that they are distributed in the eutectic phase and probably forming intermetallic compounds.

\subsection{X-ray diffraction analysis}

In order to have a better comprehension of eutectic phase the patterns of the X-ray diffraction are shown in Fig. 7. Additional samples of pure Ti6Al4V and CoCrMo were sintered at $1260{ }^{\circ} \mathrm{C}$ and their diffraction patterns are added in Fig. 7. For the Ti6Al4V the peaks of the $\alpha$ and $\beta$ phases were obtained ${ }^{34}$. On the other hand, for the CoCrMo, characteristic peaks of such alloy at the main planes were found $\left(110,200\right.$ and 220) ${ }^{18}$. Composite samples present the main peaks of the CoCrMo and the main peak of $\alpha$-Ti phase. 

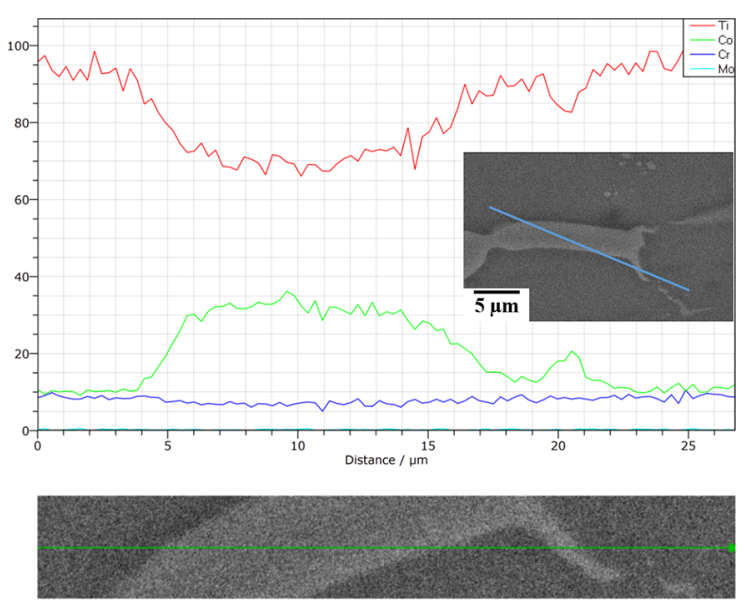

Figure 6. Line analysis across the eutectic phase for a sample sintered at $1130^{\circ} \mathrm{C}$.

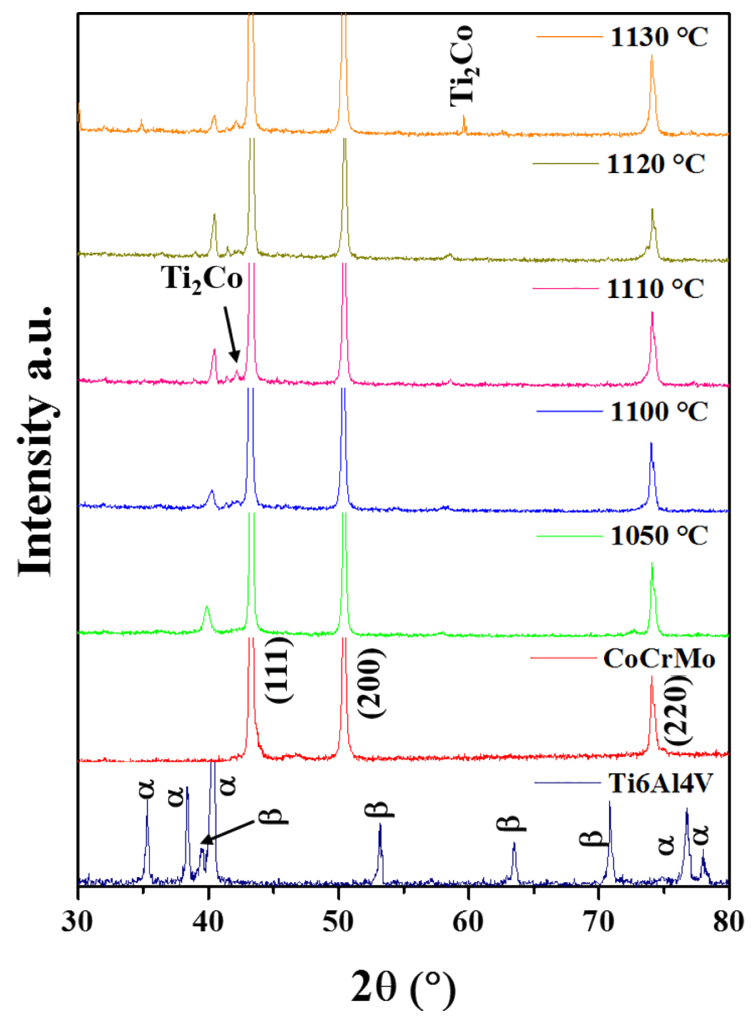

Figure 7. XRD patterns of samples sintered at different temperatures.

Samples sintered at $1100^{\circ} \mathrm{C}$ and above show the presence of characteristic peak of the $\mathrm{Ti}_{2} \mathrm{Co}$ phase at $42.2^{\circ}$, which is related to the eutectic phase created during sintering ${ }^{34}$. This indicates that first the surface of Ti6Al4V particles is enriched by Co from the contacts with the CoCrMo particles, until the atomic relationship to form the semi-solid solution of the $\mathrm{Ti}_{2} \mathrm{Co}$ is reached and then when the temperature increases above $1120^{\circ} \mathrm{C}$, the liquid phase appears in the microstructure to fill interparticle pores, reaching higher values of densification.

\subsection{Microhardness}

Values of the microhardness obtained on the polished surfaces are listed in Table 1. In order to have reference values, samples of Ti6Al4V and CoCrMo that were sintered at $1260{ }^{\circ} \mathrm{C}$ under argon atmosphere were indented as well as the composite samples. Indentations on the surface of composites were made on the matrix and $\mathrm{Ti}_{2} \mathrm{Co}$ phase, that can be easily distinguished in the optical microscope used in the microhardness tester. With the aim to illustrate the process of microindentation performed on the 2 phases of the composite SEM micrographs are shown in Fig. 8. It can be noticed that the square-based diamond print of the indenter left on the matrix is bigger than the one left on the $\mathrm{Ti}_{2} \mathrm{Co}$ phase, which indicates that $\mathrm{Ti}_{2} \mathrm{Co}$ is harder than the matrix.

The results of microhardness test taken from the regular samples indicated the value of 350 and $401 \mathrm{HV}$ for the Ti6Al4V and CoCrMo, respectively. This values are in agreement with those reported for both kind of alloys sintered or fabricated by casting 19,40 , and 41 . The values of microhardness $\left(\mathrm{HV}_{0.01}\right)$ found for the Ti6Al4V matrix of the composite, increased $40 \%$ with respect to the reference value, from 350 up to $487 \mathrm{HV}$. This could be explained by the fact that the eutectic phase acts by compressing the matrix particles during densification. It could be also possible that strengthening is achieved during the cooling due to the different thermal coefficients, which generates stresses that improve the microhardness of the matrix, as it was pointed out by Casati and Vedani ${ }^{42}$. On the other hand, the values obtained for the eutectic phase increased as the sintering temperature augmented, indicating a value 2 times larger than the matrix and 1.8 times larger than that of the CoCrMo alloy. The increment of the microhardness is associated to the enrichment of $\mathrm{Co}$ in the eutectic phase until it reaches the

Table 1. Microhardness values of composites sintered at different temperatures. Reference values of samples of Ti6Al4V and CoCrMo sintered at $1260{ }^{\circ} \mathrm{C}$ are included.

\begin{tabular}{|c|c|c|c|}
\hline Sample & Matrix & $\begin{array}{l}\text { Eutectic Ti/ } \\
\quad \text { Co }\end{array}$ & $\begin{array}{c}\text { Average } \\
\text { value of } \\
\text { whole sample }\end{array}$ \\
\hline $\begin{array}{l}\text { CoCrMo at } \\
1260^{\circ} \mathrm{C}\end{array}$ & -- & -- & 401 \\
\hline $\begin{array}{l}\text { Ti6Al4V at } \\
1260^{\circ} \mathrm{C}\end{array}$ & -- & -- & 350 \\
\hline $\begin{array}{l}\text { Ti6Al4V/ } \\
\text { CoCrMo at } \\
1100{ }^{\circ} \mathrm{C}\end{array}$ & 481 & 593 & -- \\
\hline $\begin{array}{l}\text { Ti6Al4V/ } \\
\text { CoCrMo at } \\
1120^{\circ} \mathrm{C}\end{array}$ & 485 & 698 & -- \\
\hline $\begin{array}{l}\text { Ti6Al4V/ } \\
\text { CoCrMo at } \\
1130{ }^{\circ} \mathrm{C}\end{array}$ & 487 & 734 & -- \\
\hline
\end{tabular}



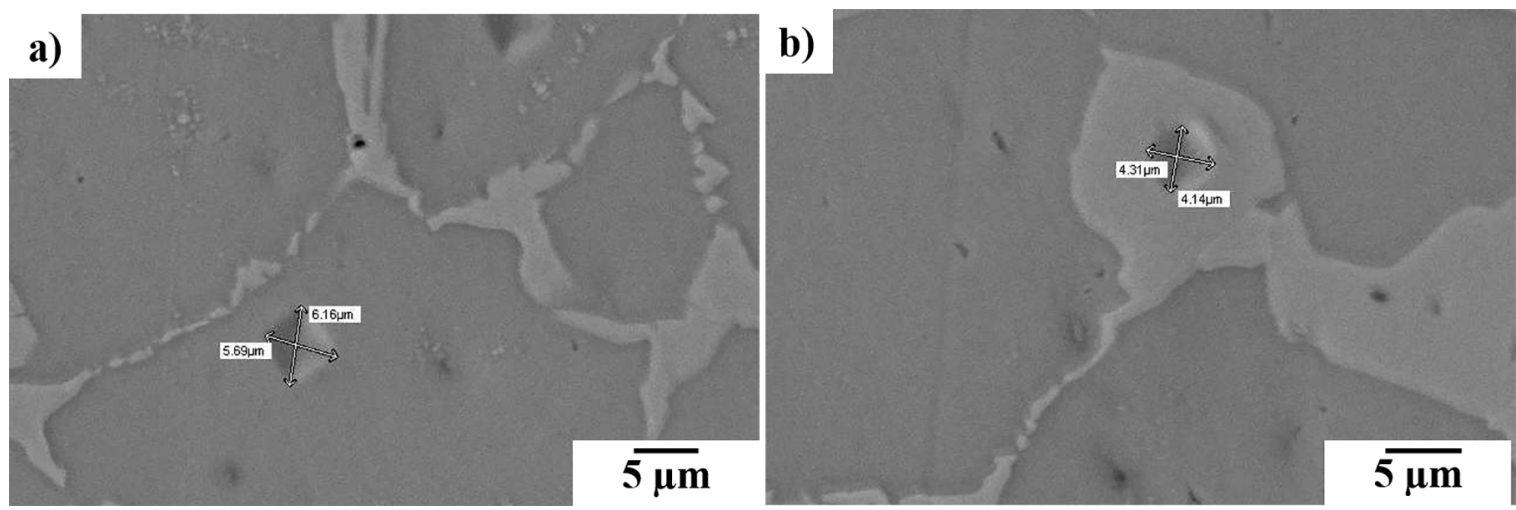

Figure 8. SEM micrographs of the microhardness indentations on both phases of the composite: a) matrix and b) eutectic $\mathrm{Ti}_{2} \mathrm{Co}$ phase.

atomic relationship of the $\mathrm{Ti}_{2} \mathrm{Co}$ phase. The microhardness values of the eutectic phase found are higher than those reported for the cast and heat treated alloys of Ti-Co, used in dental implants ${ }^{30}$. This values are in agreement with those reported by Vamsi Krishna et al. ${ }^{18}$ for coatings of $\mathrm{CoCrMo} /$ Ti6A14V produced by LENS technique.

\section{Conclusions}

A composite of Ti6Al4V reinforced with CoCrMo particles was fabricated by the semi-solid sintering process and characterized by means of SEM and X-ray diffraction.

From dilatometry tests it was determined the temperature of liquid phase formation, which highly increased the densification of composites, obtaining samples with $93 \%$ relative density.

The microstructure evolution as a function of the temperature was observed by SEM images and it was determined the formation mechanism of the eutectic phase and the pathway followed by the liquid to densify the composite. A good distribution of the matrix and of the eutectic phase was demonstrated. This is due to the good distribution of the CoCrMo particles in the initial packing, probably because both matrix and reinforcing particles have similar shape and size.

It was assessed from the $\mathrm{X}$-ray patterns that the eutectic phase is composed of $\mathrm{Ti}_{2} \mathrm{Co}$ intermetallic compound and it seems to be formed at a temperature of $1100^{\circ} \mathrm{C}$ and above.

The values of the microhardness obtained are higher than those reported in the literature for casting alloy of Ti-Co and also for regular alloys of Ti6Al4V and CoCrMo, which is promising for dental and/or orthopedic implants in where the hardness is important, by assuming the both alloys have a good biocompatibility.

\section{References}

1. Rack HJ, Qazi JI. Titanium alloys for biomedical applications. Materials Science and Engineering: C. 2006;26(8):1269-1277.
2. Dourandish M, Godlinski D, Simchi A, Firouzdor V. Sintering of biocompatible P/M Co-Cr-Mo alloy (F-75) for fabrication of porosity-graded composite structures. Materials Science and Engineering: A. 2008;472(1-2):338-346.

3. Rodrigues WC, Broilo LR, Schaeffer L, Knörnschild G, Espinoza FRM. Powder metallurgical processing of Co- $28 \% \mathrm{Cr}-6 \% \mathrm{Mo}$ for dental implants: Physical, mechanical and electrochemical properties. Powder Technology. 2011;206(3):233-238.

4. España FA, Balla VK, Bose S, Bandyopadhyay A. Design and fabrication of CoCrMo alloy based novel structures for load bearing implants using laser engineered net shaping. Materials Science and Engineering: C. 2010;30(1):50-57.

5. Wang X, Xu S, Zhou S, Xu W, Leary M, Choong P, et al. Topological design and additive manufacturing of porous metals for bone scaffolds and orthopaedic implants: A review. Biomaterials. 2016;83:127-141.

6. Bahraminasab M, Sahari BB, Edwards KL, Farahmand F, Arumugam M, Hong TS. Aseptic loosening of femoral components - A review of current and future trends in materials used. Materials \& Design. 2012;42:459-470.

7. Shen H, Brinson LC. A numerical investigation of porous titanium as orthopedic implant material. Mechanics of Materials. 2011;43(8):420-430.

8. Karageorgiou V, Kaplan D. Porosity of 3D biomaterial scaffolds and osteogenesis. Biomaterials. 2005;26(27):5474-5491.

9. Takemoto M, Fujibayashi S, Neo M, Suzuki J, Kokubo T, Nakamura T. Mechanical properties and osteoconductivity of porous bioactive titanium. Biomaterials. 2005;26(30):60146023.

10. Reig L, Amigó V, Busquets DJ, Calero JA. Development of porous Ti6A14V samples by microsphere sintering. Journal of Materials Processing Technology. 2012;212(1):3-7.

11. Torres Y, Rodríguez JA, Arias S, Echeverry M, Robledo S, Amigo V, et al. Processing, characterization and biological testing of porous titanium obtained by space-holder technique. Journal of Materials Science. 2012;47(18):6565-6576.

12. Cabezas-Villa JL, Olmos L, Bouvard D, Lemus-Ruiz J, Jiménez O. Processing and properties of highly porous Ti6A14V mimicking human bones. Journal of Materials Research . 2018;33(6):650661. 
13. Liu YJ, Li SJ, Wang HL, Hou WT, Hao YL, Yang R, et al. Microstructure, defects and mechanical behavior of beta-type titanium porous structures manufactured by electron beam melting and selective laser melting. Acta Materialia. 2016;113:56-67.

14. Sallica-Leva E, Caram R, Jardini AL, Fogagnolo JB. Ductility improvement due to martensite a\&apos; decomposition in porous Ti-6Al-4V parts produced by selective laser melting for orthopedic implants. Journal of the Mechanical Behavior of Biomedical Materials. 2016;54:149-158.

15. Parthasarathy J, Starly B, Raman S, Christensen A. Mechanical evaluation of porous titanium (Ti6Al4V) structures with electron beam melting (EBM). Journal of the Mechanical Behavior of Biomedical Materials. 2010;3(3):249-259.

16. Lin XZ, Zhu MH, Zheng JF, Luo J, Mo JL. Fretting wear of microarc oxidation coating prepared on Ti6A14V alloy. Transactions of Nonferrous Metals Society of China. 2010;20(4):537-546.

17. Wendler BG, Pawlak W. Low friction and wear resistant coating systems on Ti6Al4V alloy. Journal of Achievements in Materials and Manufacturing Engineering. 2008;26(2):207-210.

18. Krishna BV, Xue W, Bose S, Bandyopadhyay A. Functionally graded Co-Cr-Mo coating on Ti-6Al-4V alloy structures. Acta Biomaterialia. 2008;4(3):697-706.

19. Chávez J, Olmos L, Jiménez O, Bouvard D, Rodríguez E, Flores M. Sintering behaviour and mechanical characterisation of Ti64/ xTiN composites and bilayer components. Powder Metallurgy. 2017;60(4):257-266.

20. Cho M, Hong E, So J, Song M, Kim BS, Yamamoto A, et al. Tribological properties of biocompatible Ti-10W and Ti-7.5TiC7.5W. Journal of the Mechanical Behavior of Biomedical Materials. 2014;30:214-222.

21. Yan Z, Chen F, Cai Y, Zheng Y. Microstructure and mechanical properties of in-situ synthesized $\mathrm{TiB}$ whiskers reinforced titanium matrix composites by high-velocity compaction. Powder Technology. 2014;267:309-314.

22. Huang LJ, Geng L, Xu HY, Peng HX. In situ TiC particles reinforced Ti6Al4V matrix composite with a network reinforcement architecture. Materials Science and Engineering: A. 2011;528(6):2859-2862.

23. Krasicka-Cydzik E, Oksiuta Z, Dabrowski JR. Corrosion testing of sintered samples made of the Co-Cr-Mo alloy for surgical applications. Journal of Materials Science: Materials in Medicine. 2005;16(3):197-202.

24. Varano R, Bobyn JD, Medley JB, Yue S. Effect of microstructure on the dry sliding friction behavior of CoCrMo alloys used in metal-on-metal hip implants. Journal of Biomedical Materials Research. Part B: Applied Biomaterials. 2006;76(2):281-286.

25. Song CB, Park HB, Seong HG, López HF. Development of athermal e-martensite in atomized Co-Cr-Mo-C implant alloy powders. Acta Biomaterialia. 2006;2(6):685-691.

26. Kim HR, Kim YK, Son JS, Min BK, Kim KH, Kwon TY. Comparison of in vitro biocompatibility of a $\mathrm{Co}-\mathrm{Cr}$ dental alloy produced by new milling/post-sintering or traditional casting technique. Materials Letters. 2016;178:300-303.
27. Koutsoukis T, Zinelis S, Eliades G, Al-Wazzan K, Rifaiy MA, Al Jabbari YS. Selective Laser Melting Technique of Co-Cr Dental Alloys: A Review of Structure and Properties and Comparative Analysis with Other Available Techniques. Journal of Prosthodontics. 2015;24(4):303-312.

28. Yamanaka K, Mori M, Kuramoto K, Chiba A. Development of new Co-Cr-W-based biomedical alloys: effects of microalloying and thermomechanical processing on microstructures and mechanical properties. Materials \& Design. 2014;55:987-998.

29. Mutlu I. Synthesis and characterization of Ti-Co alloy foam for biomedical applications. Transactions of Nonferrous Metals Society of China. 2016;26(1):126-137.

30. Wang R, Welsch G. Evaluation of an experimental Ti-Co alloy for dental restorations. Journal of Biomedical Materials Research. Part B: Applied Biomaterials. 2013;101(8):1419-1427.

31. Rhines FN. Phase Diagrams in Metallurgy. New York: McGrawHill; 1956.

32. Fan Z. Semisolid metal processing. International Materials Reviews. 2002;47(2):49-85.

33. Yang C, Kang LM, Li XX, Zhang WW, Zhang DT, Fu ZQ, et al. Bimodal titanium alloys with ultrafine lamellar eutectic structure fabricated by semi-solid sintering. Acta Materialia. 2017; 132:491-502.

34. Kang LM, Yang C, Wang F, Li XX, Zhu DZ, Zhang WW, et al. Designing ultrafine lamellar eutectic structure in bimodal titanium alloys by semi-solid sintering. Journal of Alloys and Compounds. 2017;702:51-59.

35. Liu LH, Yang C, Yao YG, Wang F, Zhang WW, Long Y, et al. Densification mechanism of Ti-based metallic glass powders during spark plasma sintering process. Intermetallics. 2015;66:1-7.

36. Frenkel J. Viscous flow of crystalline bodies under the action of surface tension. The Journal of Physics, USSR. 1945;9:385-391.

37. Yang C, Zhu MD, Luo X, Liu LH, Zhang WW, Long Y, et al. Influence of powder properties on densification mechanism during spark plasma sintering. Scripta Materialia. 2017;139:96-99.

38. Xu X, Nash P. Sintering mechanisms of Armstrong prealloyed Ti-6Al-4V powders. Materials Science and Engineering: $A$. 2014;607:409-416.

39. Wang J, Raj R. Estimate of the Activation Energies for Boundary Diffusion from Rate-Controlled Sintering of Pure Alumina, and Alumina Doped With Zirconia or Titania. Journal of the American Ceramic Society. 1990;73(5):1172-1175.

40. Abdul Hamid MH, Fadzil FSM, Selamat MA, Ahmad MA. Sintering Effects on the Microstructure and Mechanical Properties of CoCrMo Alloy. Advanced Materials Research. 2016;1133:259263.

41. Henriques B, Soares D, Silva FS. Microstructure, hardness, corrosion resistance and porcelain shear bond strength comparison between cast and hot pressed CoCrMo alloy for metal-ceramic dental restorations. Journal of the Mechanical Behavior of Biomedical Materials. 2012;12:83-92.

42. Casati R, Vedani M. Metal Matrix Composites Reinforced by Nano-Particles-A Review. Metals. 2014;4:65-83. 